\title{
Evaluation of Pesticide Residues in Mango by a Multi-residue Analysis and GC/MS Triple Quadrupole
}

\author{
Claudia Helena Pastor Ciscato ${ }^{1}$, Kumi Shiota Ozawa ${ }^{2}$, Claudia Maria Barbosa ${ }^{1}$ and Amir Bertoni Gebara ${ }^{1}$ \\ 1. Instituto Biológico, Laboratório de Resíduos de Pesticidas, 1252 Avenida Conselheiro Rodrigues Alves, 3rd Floor, São Paulo/SP, \\ Brazil \\ 2. Agilent Technologies, 1142 Araguaia Ave., 1st Floor, Barueri/SP, Brazil
}

\begin{abstract}
Mango fruit has a great national and international market, and Brazilian production is 1,900 thousand tons/year exporting to North America and Europe. However, the loss could occur during the production when it is affected by pests and climate conditions, so the increased use of chemical substances and their presence should be monitored. A task for governmental agencies, producers and food sales, attending the sanitary barriers requirements, is to distribute food free from contaminants, so laboratories involved in this type of work usually employ multi-residues analysis. The objective of this study was to evaluate the presence of pesticide residues in mango using QuEChERS method and mass spectrometry technique. Positive samples were compared with Brazilian maximum residues level (MRL) and the health risk exposure was evaluated using the acute dietary intake (ADI) parameter. A total of 20 samples were collected from January to March, in Sao Paulo city markets. The recoveries were in the range of $70 \%$ to $120 \%$, and standard deviation was below $20 \%$. The category of pesticides not permitted for the crop were found in 10 samples; eight samples presented pesticides below MRL and two samples above MRL for the fungicide procloraz. The ADI values were below $20 \%$ of ADI for an adult and the worst case was dimethoate with $69 \%$ of ADI for children. The time spent in monitoring studies and the viability of method chosen must be considered by pesticide residues laboratories during routine analysis of food quality control.
\end{abstract}

Key words: ADI, risk exposure, mango, monitoring, multi-residue, QuEChERS, gas chromatography-mass spectrometry (GC/MS).

\section{Introduction}

Brazil is one of the great fruits producers, and exports them for all over the world. The climate condition of the country is favorable to produce fruits, like banana, melon, papaya, passion fruit and pineapple; mango is the one that has increasing consumption and consequently its production. Among the many variety of this fruit, Tommy Atkins is the favorite for exporting due to its appearance and resistance for long journeys. National data showed that Brazil exports $14 \%$ of the mango production to USA and $33 \%$ to European Community (EC). Although United States being a potential importer, they are not the main buyer of Brazilian fruit, because in most of the cases, it is hindered by sanitary and legislative barriers established by that country [1], like

Corresponding author: Claudia Helena Pastor Ciscato, Ph.D., research field: pesticide residues. pesticide residues contamination [2].

Europe is one of main buyer of Brazilian product, importing about $63 \%$ of total Brazilian fruit. Furthermore, Brazil stands out as the biggest supplier of mango, papaya and melon for European Union (EU).

Brazil places the 2nd in the pesticide usage during food production. Therefore, pesticide residues monitoring analysis should be developed to guarantee the food quality control. The governmental and private laboratories involved in this type of work usually employ multi-residues analysis.

Monitoring programs developed in Brazil demonstrated that mango could be contaminated mainly by organophosphorus insecticides and fungicides. It is well known that organophosphorus compounds have a very low acute dietary intake (ADI), being a parameter which could be evaluated 
during data analysis.

The objective of this work was to evaluate the pesticide residues in mango purchased at local supermarket to verify the compliance with the maximum residues limits (MRL) established by Brazilian legislation [3], as well as ADI parameter of positive samples was evaluated. The samples were extracted by time and cost saving QuEChERS sample preparation method and analyzed by Agilent 7000B triple quadrupole GC/MS system.

\section{Materials and Methods}

A total of 20 samples were collected during the main period of production and were evaluated by a screening and quantitative method. The sample preparation was performed using the QuEChERS method [4].

\subsection{Sample Characteristics}

The mango fruit has as constituents of $0.2 \%$ lipids, 14.5\% carbohydrates, $0.03 \%$ ascorbic acid and $0.6 \%$ carotene. The low volatile compounds, such as carotene, mango's pigments, can deposit on analyte flow path of GC/MS system requiring its maintenance more often to get reliable results. The kit containing graphitized carbon black (GCB) was employed in the dispersive solid phase extraction (dSPE) step to improve the cleanup of the extract.

\subsection{Analytical Steps}

\subsubsection{Multi-residues Method of QuEChERS}

The sample was chopped including the peel, blended and homogenized. The aliquot of $10 \mathrm{~g}$ was extracted in $50 \mathrm{~mL}$ centrifuge tube by using acetonitrile for $1 \mathrm{~min}$ in vortex; a mix of salts $\left(\mathrm{MgSO}_{4}\right.$, $\mathrm{NaCl}$ and buffering citrates salts, EN kit QuEChERS Agilent p/n 5982-5650 CH) was used. The extract was shaken vigorously (1 $\mathrm{min}$ ) and again centrifuged (5,000 rpm for $1 \mathrm{~min}$ ). Cleanup step was performed using primary secondary amine (PSA) with GCB and $\mathrm{MgSO}_{4}$ (dispersive SPE kit from Agilent for pigmented fruit and vegetables $\mathrm{p} / \mathrm{n}$ 5982-5256CH), and further 1 min centrifugation at 6,000 rpm was employed. Then, the supernatant was evaporated and reconstituted with isooctane and $1 \mu \mathrm{L}$ was injected into GC/MS/MS (Agilent 7000B triple quadrupole system).

\subsubsection{Fortification Step}

A standard solution of a mixture of 28 pesticides selected from monitoring data amenable to gas chromatography (GC) technique was prepared at concentration of $0.25,0.5$ and 1 times of MRL, and $100 \mu \mathrm{L}$ of this mixture was used to fortify the samples for validation study. After standing for $30 \mathrm{~min}$, the samples were extracted.

\subsubsection{Standard Solution and Reagents}

As pure standards from Accustandard, around 99\% of purity was used to prepare a mixture of 28 pesticides belonging to different chemical groups. Triphenyl phosphate (TPP) was added after the cleanup step as internal standard. The dSPE mixture contains graphitized carbon to clean up the pigments, but it also can retain TPP. In order to avoid this interaction, the addition of internal standard was performed soon before injection.

Five-level calibration curve was prepared using blank mango extract, adding correspondent concentrations to have $0.25,0.5,1,2.5$ and 5 times MRL of respective pesticides.

The mixture of 258 pesticides for screening method was prepared at concentration of $0.1 \mathrm{mg} / \mathrm{kg}$.

All solvents and reagents are high purity or pesticide residues analysis grade.

\subsubsection{Chromatography Conditions}

The triple quadrupole GC/MS system was equipped with a split/splitless injection inlet. Samples were injected at $1 \mu \mathrm{L}$ volume in splitless mode into HP-5msUI (30 m length $\times 0.32 \mathrm{~mm}$ inner diameter and $0.25 \mu \mathrm{m}$ film thickness) with deactivated capillary tubing $(0.7 \mathrm{~m} \times 0.15 \mathrm{~mm})$ connected by purged ultimate union for back flushing the main column. Oven temperature was first $90{ }^{\circ} \mathrm{C}$ holding $0.5 \mathrm{~min}$, to 
$200{ }^{\circ} \mathrm{C}\left(50{ }^{\circ} \mathrm{C} / \mathrm{min}\right)$ for $0.5 \mathrm{~min}, 200{ }^{\circ} \mathrm{C}$ to $230{ }^{\circ} \mathrm{C}$ ( $3{ }^{\circ} \mathrm{C} / \mathrm{min}$ ) holding $1 \mathrm{~min}, 230^{\circ} \mathrm{C}$ to $250^{\circ} \mathrm{C}\left(6^{\circ} \mathrm{C} / \mathrm{min}\right)$ holding $5 \mathrm{~min}, 250{ }^{\circ} \mathrm{C}$ to $280^{\circ} \mathrm{C}\left(30^{\circ} \mathrm{C} / \mathrm{min}\right)$ holding $3 \mathrm{~min}$, then $5^{\circ} \mathrm{C} / \mathrm{min}$ until final temperature of $285^{\circ} \mathrm{C}$ (2 min). The splitless injection system was at $230^{\circ} \mathrm{C}$ and hold $2 \mathrm{~min}$, and ion source temperature was at $300{ }^{\circ} \mathrm{C}$. The gas flow rate was $1 \mathrm{~mL}$ carrier gas (helium)/min.

Two methods were employed to verify the pesticide residues contamination, a multi-residue method for screening purpose without calibration curve and another for quantitative method to accurately calculate the pesticide concentration in the sample. Although not having the calibration curve for screening method, after the detection of the compound, the confirmation with the known concentration standard was injected to calculate the concentration in the sample as shown in Table 1.

\subsubsection{Toxicological Evaluation}

The percentage of ADI was calculated using the value of $3.45 \mathrm{~g} / \mathrm{d}$ of mango consumption, according to Instituto Brasileiro de Geografia e Estatística (IBGE) —Brazilian Institute of Geography and Statistics [5]. According to GEMS [6], the mango consumption around the world is: Middle Eastern $2.3 \mathrm{~g} / \mathrm{d}$; Far Eastern 5.3 g/d; African 3.4 g/d; Latin American 6.3 $\mathrm{g} / \mathrm{d}$ and Europe none or insignificant. In Brazil, the risk exposure of some food items was evaluated by the methods described in Refs. [7-9].

\section{Results and Discussion}

According to Brazilian legislation, 10 samples presented that pesticides were not permitted for the crop; pesticides below the MRL were found in eight samples and two samples were above the MRL. All the samples evaluated in this study presented a residue of pesticide, and some of them presented more than one pesticide, or multiple findings.

The fungicide procloraz was one of the substances, which had concentration level detected above the MRL (Table 1). This substance was also detected in mango samples evaluated in the national monitoring programs [10, 11].

The pesticides below MRL were: azoxystrobin, bifenthrin, chlorpyriphos, lambda-cyhalothrin, cypermethrin, fenoxaprop-p-ethyl, imazalil, pyraclostrobin, thiabendazole and trifloxystrobin, and all of them below the limit of quantification (LOQ).

Nevertheless, the pesticides above MRL values were prochloraz according to Brazilian legislation, dimethoate according to EC [7] and difenoconazole and tebuconazole according to Codex Alimentarius [8], respectively. Fungicides and insecticides are frequently used during fruit production in tropical countries. Although the values above the MRL, the toxicological parameters of ADI were not exceeded, because the higher level was about $20 \%$ of ADI. For instance, the insecticide dimethoate, which has ADI value for an adult below $10 \%$, reached $69 \%$ for the children. Despite toxicological characteristics of organophosphorus insecticides were a health concern, especially because mango fruit is frequently used in infant formulas and also could be consumed fresh by children. For other substances, like difenoconazole and tebuconazole, the concentrations detected in most of the samples were about $5 \%$ of children's ADI. In some cases, they were detected with other pesticides, being considered multiple findings, which is well known to contribute more in some toxicological events [7, 9, 12]. Deterministic evaluation helps to demonstrate in a single way which substance could offer a health risk exposure to the consumers.

Governmental agencies using the data from monitoring programs and results from routine laboratories could verify the food compliance with such parameters guaranteeing the safe food consumption. MRL values demonstrated the good agricultural practices. Both results are used regularly.

The multiple findings occurred in 19 samples, being considered a health risk concern due to a large exposure to the contaminants. Only one sample had one active substance pyraclostrobin. The worst case was 
Table 1 Results from mango samples purchased at local markets.

\begin{tabular}{|c|c|c|c|c|c|c|c|c|c|c|c|c|c|c|c|c|c|c|c|c|c|c|}
\hline \multirow[b]{2}{*}{ Pesticide } & \multicolumn{2}{|r|}{ MRL } & \multicolumn{20}{|c|}{ Samples purchased at local markets } \\
\hline & $\begin{array}{l}\text { Brazil } \\
{[11]}\end{array}$ & $\begin{array}{l}\text { Codex } \\
\text { [13] }\end{array}$ & $\begin{array}{l}\mathrm{EU} \\
114]\end{array}$ & 2 & 3 & 4 & 5 & 6 & 7 & 8 & 9 & 10 & 11 & 12 & 13 & 14 & 15 & 16 & 17 & 18 & 19 & 20 \\
\hline Azoxystrobin & 0.30 & & 0.70 & & $<0.05$ & $<0.05$ & $<0$. & & & & & & $<0$. & & & $<0.05$ & $<0.05$ & $<0.05$ & $<0.05$ & $<0.05$ & & $<0.05$ \\
\hline Carbosulfan & 0.05 & & 0.01 & & & & & & & & & & & & & & & & & & & \\
\hline Chlorpyriphos & & & 0.05 & & & & & & & $<0.01$ & & & & & & & & $<0.01$ & & & & \\
\hline Lambda-cyhalothrin & 0.10 & 0.20 & 0.20 & & & & & & $<0.03$ & & & & & & & & $<0.03$ & & & & $<0.03$ & \\
\hline Cypermethrin & 0.70 & 0.70 & 0.70 & & & $<0.03$ & & & & & & & & $<0.0$ & & $<0.03$ & $<0.03$ & & & & $<0.03$ & \\
\hline Diazinon & & & 0.01 & & & & & & & & & & & & & & & & & & & \\
\hline Difenoconazole & 0.20 & 0.07 & 0.10 & & & & & & & & & & & $<0.0$ & & & $<0.05$ & 0.22 & $<0.05$ & 0.06 & & $<0.05$ \\
\hline Dimethoate & & 0.20 & 0.02 & & & & & & & 0.60 & & & & & & & & & & & & \\
\hline $\begin{array}{l}\text { Endosulfan } \\
\text { (alpha, beta and } \\
\text { sulphide) }\end{array}$ & & 0.50 & 0.05 & & & & & & & & & & & & & & & & & & & \\
\hline Ethion & & & 0.01 & & & & & & & & & & & & & & & & & & & \\
\hline Ethofenprox & 0.30 & & 0.01 & & & & & & & & & & & & & & & & & & & \\
\hline Famoxadone & 0.20 & & 0.02 & & & & & & & & & & & & & & & & & & & \\
\hline Fenoxaprop-p-ethyl & & & 0.10 & & & & & & & $<0.01$ & & & & & & & & & & & & \\
\hline Imazalil & 1.00 & & $0.05<0.05$ & & & & $<0$. & $5<0.05$ & $5<0.05$ & $<0.05$ & & & $<0$ & $5<0.0$ & & & 0.05 & & & & & \\
\hline Kresoxim-methyl & 0.20 & & 0.05 & & & & & & & & & & & & & & & & & & & \\
\hline Lindane & & & 0.01 & & & & & & & & & & & & & & & & & & & \\
\hline Methidathion & & & 0.02 & & & & & & & & & & & & & & & & & & & \\
\hline Mirex & & & & & & & & & & & & & $<0$ & $1<0.0$ & $1<0$. & $1<0.01$ & & $<0.01$ & & & & \\
\hline Omethoate & & & & & & & & & & 0.50 & & & & & & & & & & & & \\
\hline Permethrin & & & & & & & & & & & $<0.0$ & $<0$ & $<0$ & $3<0.0$ & $3<0$ & $3<0.03$ & & & & & & \\
\hline Phenthion & 0.05 & & 0.01 & & & & & & & & & & & & & & & & & & & \\
\hline Pyraclostrobin & 0.10 & 0.05 & 0.05 & 0.02 & & & & & & & & & & & & & & & & 0.02 & & \\
\hline Procloraz & 0.20 & & 5.00 & & & & & & $<0.05$ & & 0.92 & & & & & & & 0.85 & $<0.05$ & & & \\
\hline
\end{tabular}


(Table 1 continued)

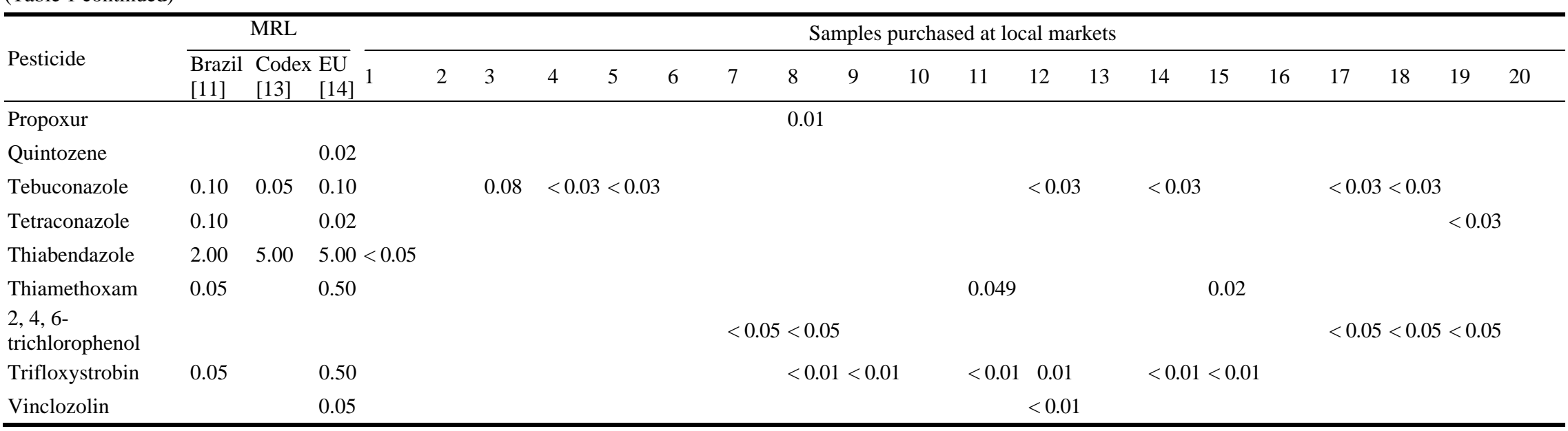


contaminated with nine different active ingredients, fungicides and insecticides. According to Ciscato et al. [15], mango fruit contains mainly carbendazim and dithiocarbamates, which are evaluated by liquid chromatography-mass spectrometry (LC-MS) and spectrophotometry by CS2 evaluation.

The results presented in this study showed that all samples analyzed were contaminated by pesticide residues, indicating that monitoring programs are important to verify the compliance with MRL and promote safe food consumption for the population.

\section{Conclusions}

The method demonstrated that even without an exhaustive cleanup, the matrix did not present an evident interference in tandem mass spectrometry technique. The screening method had the purpose to check the presence of not permitted ones, which were confirmed by the injection of the known concentration of standard after the suspect of its presence. The LOQs were near or below the MRL providing good results.

The concentrations found in the samples were below the ADI toxicological parameter, even above the MRL. However, the multiple pesticide detection could be a concern, as there is no further study about how this multiple contamination can affect our health by continuous intake. Consequently, the analytical method requires more comprehensive as possible to promote safeness of food consumption.

\section{Acknowledgments}

The authors would like to thank the Agilent Technologies for providing QuEChERS consumables and technical support.

\section{References}

[1] Nacheriner, M. L., Santos, R. R. P., and Boteon, M. 2015. "Related Markets: The Brazilian Fruit and the International Market.” Accessed October 20, 2015. http://www.cepea.esalq.usp.br/pdf/janelas.pdf. Portuguese)
[2] Sansavini, S. 2006. "The Role of Research and Technology in Shaping a Sustainable Fruit Industry: European Advances and Prospects.” Rev. Bras. Fruticultura 28 (3): 550-8.

[3] National Agency of Sanitary Surveillence (ANVISA). “Monography_Pesticides.” Accessed December 2, 2015. http://portal.anvisa.gov.br/registros-e-autorizacoes/agroto xicos/produtos/monografia-de-agrotoxicos.

(in Portuguese)

[4] Anastassiades, M., Lehotay, S. J., Stajnbaher, D., and Schenck, F. J. 2003. "Fast and Easy Multiresidue Method Employing Acetronitrile Extraction/Partitioning and Dispersive Solid-Phase Extraction for the Determination of Pesticide Residues in Produce.” JAOAC International 86 (2): 412-31.

[5] Brazilian Institute of Geography and Statistics (IBGE). 2011. "Evaluation of Per Capital Food Consumption in Brazil.” Accessed May 2016. http://www.ibge.gov.br/home/estatistica/populacao/condi caodevida/pof/2008_2009_analise_consumo/. (in Portuguese)

[6] World Health Organization. 2003. GEMS/Food Regional Diets: Regional per Capita Consumption of Raw and Semi-Processed Agricultural Commodities. The Global Environment Monitoring System, Food Contamination Monitoring and Assessment Program (GEMS/Food).

[7] Jardim, A. N. O., and Caldas, E. D. 2009. "Human Exposure to Chemical Substances Potentially Toxics to the Diet and the Health Risk.” Quimica Nova 32 (7): 1898-909. (in Portuguese)

[8] Enes, C. C., and Silva, M. V. 2005. "The Potential Pesticide Residues Ingestion through Diet and the Availability of Families from South Region in Brazil.” Revista de Higiene Alimentar 19 (136): 36-40. (in Portuguese)

[9] Caldas, E. D., and Souza, L. C. K. R. 2000. "Chronic Risk Evaluation of Pesticide Residues Ingestion from Brazilian Diet.” Journal of Public Health 34 (5): 529-37. (in Portuguese)

[10] Ministério Da Agricultura. 2015. “National Program of Control of Residues of Contaminants in Vegetable Products (PNCRC/Vegetable)." Accessed August 07, $2015 . \quad$ http://www.agricultura.gov.br/vegetal/ qualidade-seguranca-alimentos-bebidas/alimentos/residuo s-e-contaminantes. (in Portuguese)

[11] Agência Nacional de Vigilância Sanitária (ANVISA). 2015. "National Program of Pesticide Residues Analysis in Food (PARA).” Accessed August 07, 2015. http://portal.anvisa.gov.br/wps/content/Anvisa+Portal/An visa/Inicio/Agrotoxicos+e+Toxicologia/Assuntos+de+Int eresse/Programa+de+Analise+de+Residuos + de + Agrotoxi cos+em+Alimentos. (in Portuguese)

[12] Boobis, A. R., Ossendorp, B. C., Banansiak, U., Hamey, 
P. Y., Sebestyen, I., and Moretto, A. 2008. "Cumulative Risk Assessment of Pesticide Residues in Food.” Toxicology Letters 180 (2): 137-50.

[13] Codex Standards. 2014. "Pesticide Maximum Residue Levels.” Accessed February 11, 2016. http://www.fao.org /fao-who-codexalimentarius/standards/en/.

[14] EU Pesticides Database. 2016. “Search Pesticide
Residues-Mango.” Accessed January 5, 2016. http://ec.europa.eu/food/plant/pesticides/eu-pesticides-dat abase/public/?event=homepage\&language=EN .

[15] Ciscato, C. H. P., Gebara, A. B., and Monteiro, S. H. 2009. "Pesticide Residue Monitoring of Brazilian Fruit for Export 2006-2007.” Food Additives and Contaminants 2 (2): 140-5. 